\title{
SCALING UP AND SUSTAINING SOCIAL PROTECTION UNDER COVID-19
}

\author{
Peixun Fang, Adam Kennedy, and Danielle Resnick
}

T

he COVID-19 pandemic and accompanying lockdowns have had enormous negative economic impacts and tested the resilience of people across all income levels. However, as with most crises, the poor disproportionately face the largest challenge in coping with economic shocks given their low asset base, lack of savings, and the informality of their employment. Recent estimates suggest that as many as 140 million people could be pushed into extreme poverty by the crisis, threatening gains made in the fight against poverty, food insecurity, and malnutrition in the last decade (Laborde, Martin, and Vos 2020). Social safety net policies have expanded considerably during the pandemic, helping to prevent vulnerable populations from falling further into poverty and supporting households' recovery following the pandemic. This brief summarizes some of the patterns that have emerged, using data from the COVID-19 Policy Response (CPR) Portal to better identify how governments are targeting their efforts, which groups they are prioritizing, and whether citizens are satisfied with these interventions.

\section{FOOD AID AND CASH TRANSFERS ARE PRIMARY RESPONSES}

Social protection policies have been adopted by almost every country in the CPR Portal. Food aid policies are the most common, accounting for about 30 percent of all social protection policies (Figure 1). India's Pradhan Mantri Garib Kalyan Anna Yojana (PMGKAY) program, ${ }^{1}$ which targets nearly 800 million people, is one example; it gives $5 \mathrm{~kg}$ of food grain and $1 \mathrm{~kg}$ dal for free to each person/month provided they hold a ration card. Countries such as Ghana, Honduras, Kyrgyzstan, Myanmar, Senegal, and Sudan have similar programs that deliver baskets of essential foods consisting primarily of staple grains, oils, and pulses.

The other common food-related social protection policy is food price controls, which accounted for 11 percent of all social protection policies. ${ }^{2}$ Twelve countries in the database have enacted price freezes for essential foods and personal hygiene products, while others are drawing down food reserves or
FIGURE 1 Distribution of policy types

within social protection

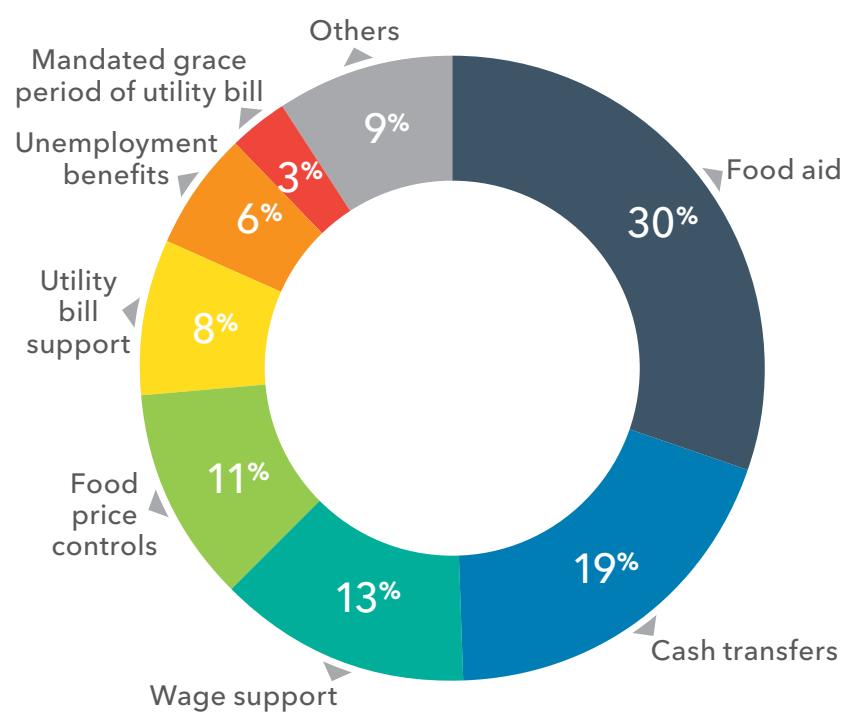

Source: Calculated from IFPRI (2020).

Note: The "Others" category includes such polices as expanded credit options, rent support, consumer food subsidies, pension increase, and school fee waivers. 
procuring staples from neighboring countries to ensure that prices do not escalate.

Cash transfer programs are the second most common response, accounting for about 19 percent of the policies reported in the CPR. Many of these initiatives draw on existing infrastructure to scale up programs that are already in place, quickly getting aid to those already enrolled. Cash transfer programs such as those in China, India, Myanmar, and Sri Lanka have taken this approach, increasing the amounts of cash distributed to beneficiaries. A few other countries have taken a slightly different approach, opting instead to expand coverage to include more families. Egypt, for instance, has expanded coverage of its Takaful and Karama programs to add more than 100,000 new families, while Uzbekistan has allocated more money to its social protection programs to cover benefits for an additional 70,000 families.

Given that dense living makes COVID-19 contagion more likely, and that urban residents have been disproportionately impacted by the closure of markets and the shuttering of businesses, a number of new cash transfer programs have emerged specifically for large cities. In Lagos, Nigeria, for instance, 250,000 vulnerable residents were to receive conditional cash transfers during the lockdown period. In the two largest cities of Burkina Faso, 20,000 households received CFA 20,000 (\$35.50) per month over a period of three months. In Zambia, households in the largest cities of Lusaka, Kitwe, Ndola, and Livingstone were selected to receive K 400 to $K 800$ ( $\$ 20$ to $\$ 40$ ) per month. Similar urban-focused initiatives were introduced in Egypt, Ethiopia, Mali, and Uganda. Relatedly, another new focus has been the targeting of urban informal workers who traditionally do not qualify for safety net programs and are also frequently excluded from the social protection schemes available to those in formal employment (Guven 2019). As seen in Figure 2, about 7 percent of programs in the CPR are targeted at those in the informal sector.

Several cash-transfer programs target women specifically, which can protect women's livelihoods while reducing gender inequality (Hidrobo et al. 2020). The Ehsas Emergency Cash Program in Pakistan is targeting 12 million women heads of household categorized as poor or daily wage earners. In India, the Pradhan Mantri Jan-Dhan Yojana program is targeting
FIGURE 2 Share of social protection policies that

targeted specific types of population

$30 \%$

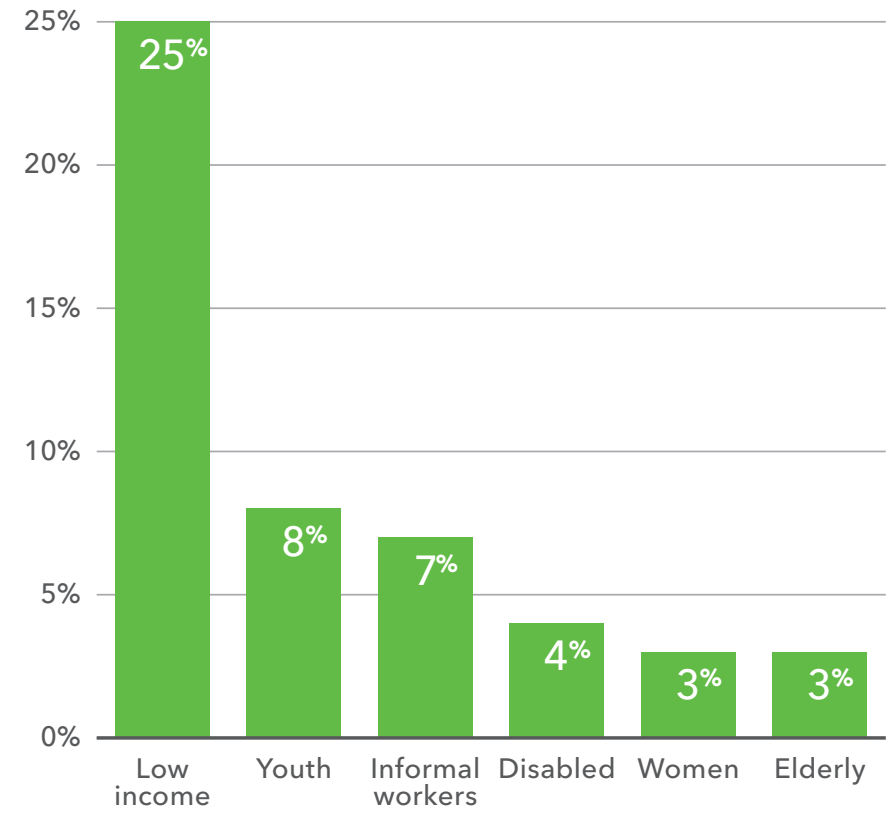

Source: Calculated from IFPRI (2020).

200 million women account holders with an additional Rs 500 (\$6.50) per month; and Uzbekistan's First Lady has allocated 5 billion soums $(\$ 492,000)$ to financially support thousands of women who are the most affected by COVID-19.

\section{NEW FORMS OF DELIVERY}

Mobile technology, which was already becoming a common modality for the distribution of cash transfers, has been used to reach large numbers of beneficiaries during the pandemic. In Bangladesh, those low-income earners who lost their livelihoods due to COVID-19 received Tk 2,500 (\$29) cash support through mobile financial services (MFS) - bKash, Rocket, Nagad, or SureCash - ahead of Eid-ul Fitr. The program targets almost 5 million poor families hit hard by the pandemic. A list of potential program beneficiaries was compiled by the Information and Communications Technology Division and the Disaster and Relief Management Ministry, using information from local government officials. This list was shared with the Finance Ministry to cross-check against other 
available databases of social protection recipients to help improve targeting. With the help of the four top MFS operators, the cash transfers are deposited directly into recipients' mobile wallets, which allows them to avoid visits to banks and local government offices to obtain their benefits. The Emergency Cash Transfer Program in Malawi similarly uses mobile money payments to support 172,000 households in major markets such as Blantyre, Lilongwe, Mzuzu, and Zomba with $\mathrm{K} 35,000$ (\$46) per month for six months, which corresponds to the minimum wage.

In Rwanda, authorities are also using ICT to improve efficiency, effectiveness, and transparency in the way food aid is distributed. The Ngira Nkugire Management system ${ }^{3}$ is an automated platform that helps identify and register people affected by the lockdown measures and removes them from recipient lists as they return to work. It also captures contributions from the private sector and donors and shows how these resources are distributed and to whom. The system ensures that beneficiaries get donations properly by validating receipt through mobile phones, thereby improving transparency.

School feeding programs in low- and middle-income countries have been effective in improving the nutrition of beneficiaries, as well as boosting school enrollment and attendance rates. As the pandemic spread and schools closed, many of these programs have been unable to operate. However, some, such as Nigeria's Home-Grown School Feeding Program, have continued to deliver nutrient-rich meals to more than 3 million households with primary-school-age children. Eligible households receive vouchers with QR codes with a date and time stamp that can be redeemed for take-home rations at one of 6,000 distribution centers.

\section{CITIZEN (DIS)SATISFACTION}

Despite good intentions, the implementation of some of these social protection measures has not been without controversy. The CPR reports almost 300 protests driven by dissatisfaction with extant social protection responses to COVID-19, or the lack thereof. In fact, in Malawi, the lack of a social protection policy package at the outset of the pandemic led to two days of anti-lockdown protests by informal traders that resulted in the postponement of lockdowns until a package was crafted.
As seen in Figure 3, two-thirds of these protests are directly related to food aid. Most of these food-related protests were concentrated in India (71), followed by Honduras (40), and Uganda (14). Grievances have centered around several issues. First, in some cases, the channels of distribution did not work well - citizens either did not receive promised food aid or chaotic distribution led to riots. Another set of protests were by those who believe they should have been entitled to food aid due to the economic impacts of COVID-19. A third set dislike the quality and/or quantity of food provided. After food aid, the second most common category of protests were demands for more utility subsidies or utility bill freezes, especially for electricity.

FIGURE 3 Distribution of protests with respect to social protection interventions

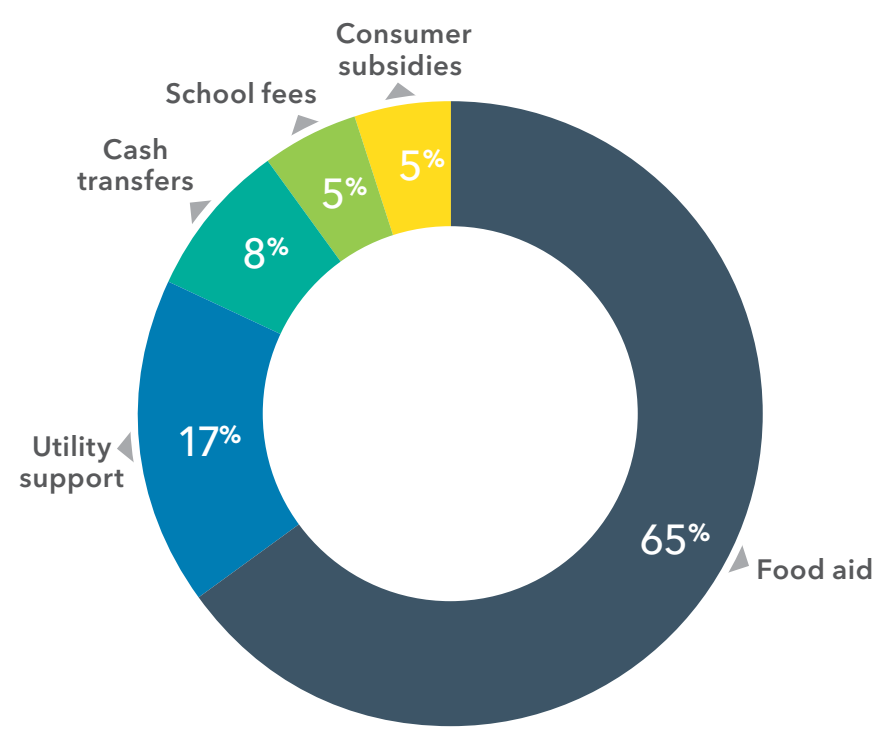

Source: "Citizen Response" data in the CPR (IFPRI 2020) as of September 18, 2020 upload.

Note: Total number of social protection-related protests in the CPR is 276 . Utility support refers to demands for utility subsidies or utility payment freezes. School fees refers to demands for fee waivers due to closed schools and canceled exams. Consumer subsidies refer to housing, child, or basic needs subsidies. By segmenting protests into these categories, we most likely understate protest behavior since many protests were about multiple grievances simultaneously.

\section{CONSISTENCY, CREDIBILITY, AND SUSTAINABILITY}

The sustainability of social protection programs is a looming question given the uncertainty about how long the pandemic will continue. Since many countries have reduced tax burdens to help households get through the crisis, the capacity of governments to

3 "Having each other's back" in Kinyarwanda. 
afford cash transfers and food aid interventions for a prolonged period is questionable without continued donor assistance. In Africa in particular, foreign aid from multilateral organizations such as the World Bank, UN organizations, and the IMF is overwhelmingly financing many of these measures. In fact, along with investments in health systems, the CPR shows that around 14 percent of foreign aid allocations for COVID-19 thus far are intended for social protection interventions. ${ }^{4} \mathrm{As}$ the crisis persists, countries will need to balance the need for fiscal consolidation and austerity with ensuring the sustainability of social protection benefits.

Beyond finances, another concern is that the misuse of money for these programs damages the legitimacy of and trust in state authorities. For instance, India's PMGKAY has been marred by corruption (Singhal 2020), and in Bangladesh, 600,000 pounds of rice intended for food aid disappeared when bureaucrats tried to sell it for higher prices (Faiola and Herrero 2020). Similarly, it is crucial that the design of these interventions does not undermine more long-term development objectives, including promoting healthy diets. Most of the food aid packages captured in the CPR are targeted at the supply and price of staple grains, with little attention paid to dietary diversity.

While it remains too early to assess which of the many social protection responses truly have cushioned the vulnerable from poverty and food insecurity, numerous examples from previous crises have demonstrated the value of these interventions in enhancing the resilience of individuals and households (Gilligan 2020). If adequately financed and implemented in a manner that is consistent with longer-term policy objectives, such interventions likely will prove to be an essential component for rebuilding livelihoods and economies in a post-pandemic world.

\section{REFERENCES}

Faiola, A., and A. V. Herrero. 2020. "A Pandemic of Corruption: \$40 Masks, Questionable Contracts, Rice-Stealing Bureaucrats Mar Coronavirus Response." Washington Post. April 26. https://www.washingtonpost.com/world/the_americas/ coronavirus-corruption-colombia-argentina-romania-bangladesh/2020/04/26/ c88a9a44-8007-11ea-84c2-0792d8591911_story.html.

Gilligan, D. 2020. "Social Safety Nets Are Crucial to the COVID-19 Response: Some Lessons to Boost Their Effectiveness." In COVID-19 and Global Food Security, edited by J. Swinnen and J. McDermott, 102-105. Washington, DC: International Food Policy Research Institute. https://doi.org/10.2499/p15738coll2.133762_23.

Guven, M. 2019. "Extending Pension Coverage to the Informal Sector in Africa." Social Protection \& Jobs Discussion Paper No.1933, World Bank, Washington, DC.

Hidrobo, M., N. Kumar, T. Palermo, A. Peterman, and S. Roy. 2020. Gender-Sensitive Social Protection: A Critical Component of the COVID-19 Response in Low- and Middle-Income Countries. IFPRI Issue Brief April 2020. Washington, DC: IFPRI. https://doi.org/10.2499/9780896293793.

Laborde Debucquet, D., W. Martin, and R. Vos. 2020. "Poverty and Food Insecurity Could Grow Dramatically as COVID-19 Spreads". In COVID-19 and Global Food Security, edited by J. Swinnen and J. McDermott, 16-19. Washington, DC: IFPRI. https://doi.org/10.2499/p15738coll2.133762_02.

Masina, L. 2020. "Judge in Malawi Blocks Government Lockdown, at Least Temporarily." Voice of America News, April 17. https://www.voanews.com/covid-19-pandemic/ judge-malawi-blocks-government-lockdown-least-temporarily.

Singhal, P. 2020. "Centre Extends Free Ration Scheme till November but Benefit Yet to Reach the Really Needy." The Indian Express, July 10. https://indianexpress.com/ article/cities/chandigarh/centre-extends-free-ration-scheme-november-benefityet-reach-needy-6498915/

4 This also includes funding for initiatives that include other objectives beyond social protection, including support for health and the economy

The COVID-19 Policy Response Portal (CPR) is managed by the International Food Policy Research Institute (IFPRI) and is financially supported by USAID and the CGIAR research program on Policies, Institutions, and Markets (PIM). This publication has been prepared as an output of the CPR. Contributing partners to the CPR include Michigan State University's Food Security Group, Global Alliance for Improved Nutrition (GAIN), Indaba Agricultural Research Institute (IAPRI) of Zambia, Tegemeo Institute of Agricultural Policy and Development of Kenya, and the Center of Studies for Peace and Development (CEPAD) of East Timor. This publication has not been independently peer reviewed. Any opinions expressed here belong to the author(s) and are not necessarily representative of or endorsed by IFPRI.

INTERNATIONAL FOOD POLICY RESEARCH INSTITUTE

A world free of hunger and malnutrition

IFPRI is a CGIAR Research Center 